\title{
Congenital dacryocystocele with intranasal extension: Correlation of computed tomography and magnetic resonance imaging
}

\author{
LARRY E. MENESTRINA, CDR, MC, USNR \\ ROBIN E. OSBORN, LCDR, MC, USNR
}

A case of dacryocystocele with intranasal extension is described by magnetic resonance imaging (MRI) characteristics, which are correlated with the appearance on computed tomography (CT) scans. Computed tomography and MRI are equally sensitive in detecting dacryocystocele. Magnetic resonance imaging has the advantages of characterizing the cyst contents, allowing multiplanar imaging without the need for manipulation of the patient, and the absence of radiation exposure. Computed tomography has the advantage of detecting bone changes involving the bony nasolacrimal canal. Clinically, these abnormalities usually resolve spontaneously and only rarely require surgical intervention.

In a review of the literature, we found only two reported cases of congenital dacryocystocele associated with intranasal extension. To our knowledge, this entity has never been described by its magnetic resonance imaging (MRI) characteristics. We report here a case in which a unilateral congenital dacryocysto-

From the Departments of Radiology and Clinical Investigation, Naval Hospital, San Diego, Calif, where at the time of this writing Dr Menestrina was a resident in diagnostic radiology; Dr Osborn is currently a staff neuroradiologist. Dr Menestrina is currently a staff radiologist at the Naval Hospital, Camp Pendleton, Calif.

The work reported herein was performed under the Navy Clinical Investigation Program, case report No. 84-16-1968-83. The views expressed in this article are those of the authors and do not reflect the official policy or position of the Department of the Navy, Department of Defense, nor the US government.

Reprint requests to LCDR Robin E. Osborn, MC, USNR, c/o Clinical Investigation Department, Naval Hospital, San Diego, CA 92134-5000. cele was accurately delineated by use of MRI and in which we correlated MRI findings with those of computed tomography (CT).

\section{Report of case}

A 10-lb, 3-day-old girl, the product of a precipitous term delivery following normal gestation, had proptosis of the right eye. Computed tomography scans of the orbits demonstrated a superior extraconal, retro-orbital mass, which proved at surgery to be an organized subperiosteal hematoma.

On physical examination, a small mass was found just inferior to the medial canthus of the right eye. Dacryoscintigraphy revealed an obstruction of the right lacrimal drainage apparatus. Computed tomography scans showed a 1 -cm cystic mass in the lacrimal fossa. The bony lacrimal fossa was expanded without evidence of frank bone destruction (Fig 1).

The bony nasolacrimal canal also was expanded with an associated cystic mass protruding into the nasal cavity. On T- ${ }_{1}$-weighted MR images, the dumbbell-shaped mass was of intermediate-signal intensity; on $\mathrm{T}_{2}$-weighted MR and proton-density images, it was of high-signal intensity (Fig 2).

On right frontal craniotomy and orbitotomy, an encapsulated retro-orbital subperiosteal mass containing dark blood was found. Pathologic examination confirmed a chronic subperiosteal intraorbital hematoma. The dacryocystocele resolved spontaneously during the infant's first week of life.

\section{Discussion}

\section{Anatomy of lacrimal drainage apparatus}

The orifices of the inferior and superior puncta within the lid margins mark the beginning of the lacrimal canaliculi (Fig 3). The canaliculi join at the medial canthus to form a common canaliculus (sinus of Maier). ${ }^{1}$ One wall of the sinus of Maier joins the lacrimal sac at an acute angle, and is termed the valve of Rosenmüller. ${ }^{2}$ 
Figure 1. Top:Dacryocystocele. Axial computed tomography secion demonstrates a smoothly demarcated, low dense mass medial to the globe (arrow). The mass extends posteriorly toward the nasolacrimal canal (small arrow). Center: Bone windows at a lower level show expansion of the lacrimal fossa and proximal nasolacrimal canal (arrows). Note the normal nasolacrimal canal on the left (curved arrow). Bottom: Dacryocystocele extends through lacrimal canal (open arrow) and bulges into the nasal cavity (arrows).

The lacrimal sac is a membranous tissue situated within a depression in the inferomedial orbital wall (lacrimal fossa). The lacrimal sac has a bulbous superior end (fundus) and a tapering body that is continuous inferiorly with the nasolacrimal duct.

The nasolacrimal duct is partly separated from the sac by valvelike folds of mucosa (valves of Krause). ${ }^{1}$ The nasolacrimal duct has two parts: the intraosseous part, which lies within the bony lacrimal canal, and the membranous part, which is $5 \mathrm{~mm}$ long and runs beneath the nasal mucosa before ending beneath the inferior nasal turbinate as a slitlike opening. ${ }^{1}$ The outlet of this nasolacrimal duct is narrowed or shut by a thin tissue membrane called Hasner's valve. ${ }^{3}$

\section{Congenital lacrimal sac distension}

The congenital form of lacrimal sac distension results from failure of perforation of the lower end of the nasolacrimal duct at Hasner's valve near the inferior meatus. ${ }^{1}$ Unlike simple nasolacrimal duct obstruction, a dacryocystocele is a hollow viscus obstructed at two ends. ${ }^{2}$ In the presence of distal obstruction, fluid accumulates in the lacrimal sac and duct, expanding the sac and collapsing the valve of Rosenmüller proximally. ${ }^{2}$ Edema or inflammation of the valve of Rosenmüller may also cause it to act as a one-way valve,${ }^{4}$ allowing fluid to enter into the lacrimal sac but preventing reflux back through the puncta.

Kinking of the common canaliculus likewise causes a functional trapdoor-type blockage when the distended sac presses on the two canaliculi. ${ }^{5}$ The net result for distension of the neonatal lacrimal sac is this coexistence of an imperforate nasolacrimal duct distally and a
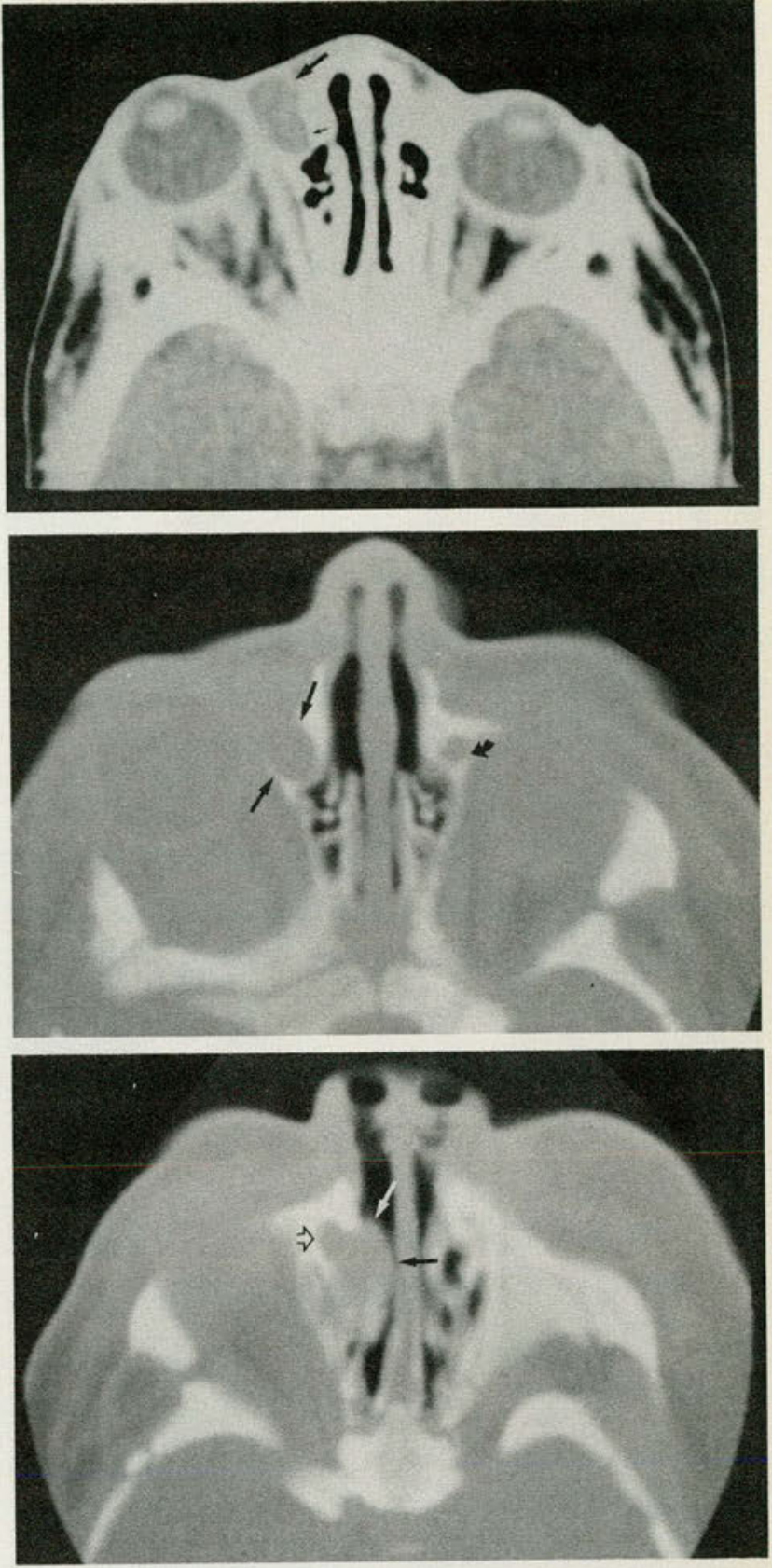

valve-like obstruction at the junction of the lacrimal canaliculi and sac proximally.

The terminology for a congenitally distended lacrimal sac varies from author to author and depends on the fluid contents in the sac. Therefore, a distended sac filled with mucus is referred to as mucocele, ${ }^{6}$ while an amniotocele describes a sac filled with amniotic fluid. ${ }^{4}$ If the sac is secondarily infected and filled with pus, it is referred to as a pyocele. Harris $^{2}$ prefers the term dacryocystocele be- 

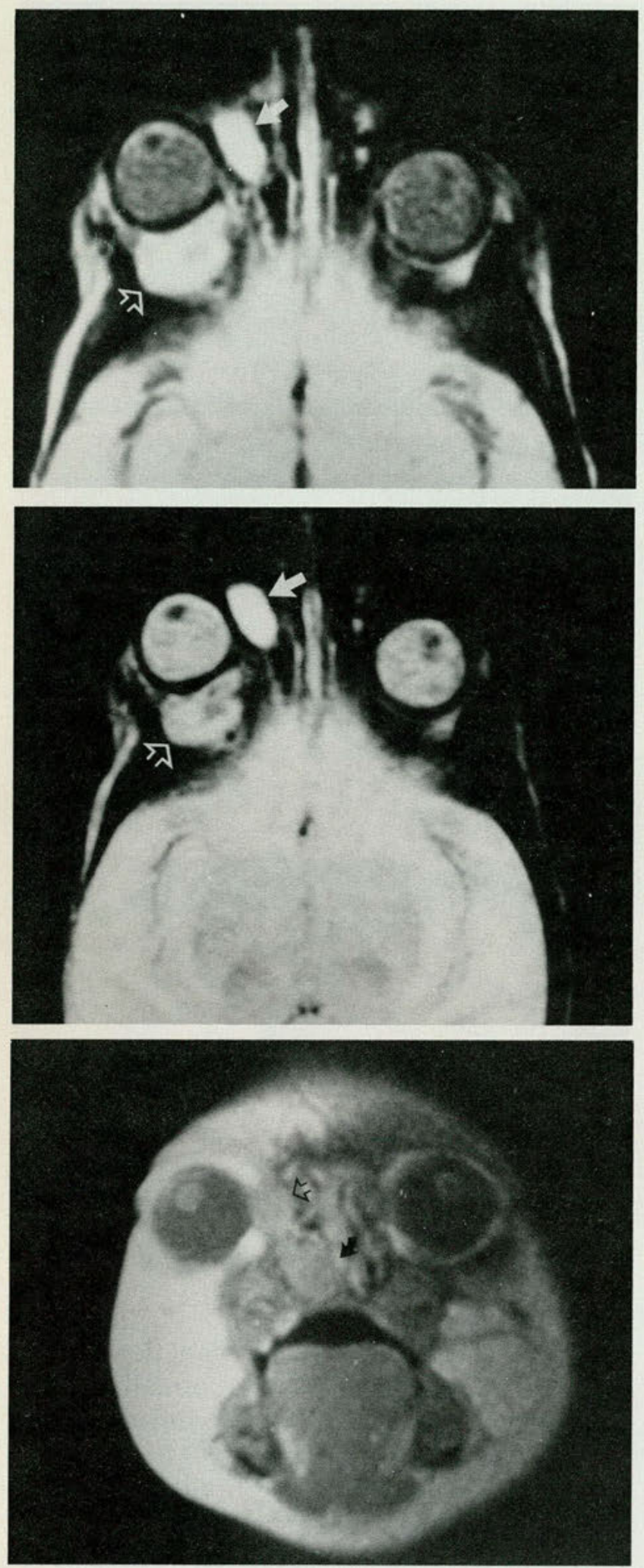

cause amniotic fluid, intrinsic mucoid secretions, tears, and the products of bacterial colonization may each be involved at some time in distension of the neonatal lacrimal sac. The
Figure 2. Top and Center: Axial intermediate- and $T_{2}$ weighted magnetic resonance images (TR 2000, TE 50 and 100) demonstrate a high-signal-intense mass within the lacrimal fossa (white arrows). The chronic subperiosteal hematoma was also delineated (open arrows). Bottom: $T_{1}$-weighted coronal image (TR 750,TE 30) accurately delineates both the intraorbital and nasal segments of the dacryocystocele.

term dacryocystocele is more specific for the anatomic anomaly and is less restrictive with regard to its fluid contents. Thus, these congenital lacrimal sac masses do not represent distinct entities but rather a continuum of the same process. ${ }^{7}$

Impatency of the nasolacrimal duct is quite common, occurring in $30 \%$ to $80 \%$ of newborn infants. $^{2,7,8}$ However, only $2 \%$ to $4 \%$ of these impatent ducts become symptomatic. ${ }^{6,7}$ The abnormality may be unilateral or bilateral $(14 \%)^{7}$. It appears as a bluish, cystic mass below the medial canthal angle. ${ }^{2}$ The vast majority $(80 \%)$ resolve spontaneously within the first 6 months of life, ${ }^{7}$ and $89 \%$ of the remainder within 13 months of age. ${ }^{2}$ The frequency of nasolacrimal duct impatency at birth suggests that congenital dacryocystocele should be more common that its infrequent reporting would indicate, and it is likely that many cases resolve spontaneously before coming to a physician's attention. ${ }^{2}$

The natural course of a congenital dacryocystocele is variable. Many will become infected and inflamed within several days and have all the characteristics of a boil with overlying swelling, erythema, and adjacent cellulitis. Most remain quiet and uninflamed until natural remission.

Management should be individualized. In the absence of acute infection, most cases can be managed conservatively with topical antibiotic ointment, warm compresses, and compressive massage. ${ }^{2,6}$ Probing is indicated in those patients who have pronounced distension of the lacrimal sac that failed to decompress or who have signs of infection ${ }^{2,6}$; however, this alternative is generally required in only $1 \%$ to $2 \%$ of cases. $^{9}$

Intranasal extension of a congenital dacryocystocele is an unusual, infrequently re- 


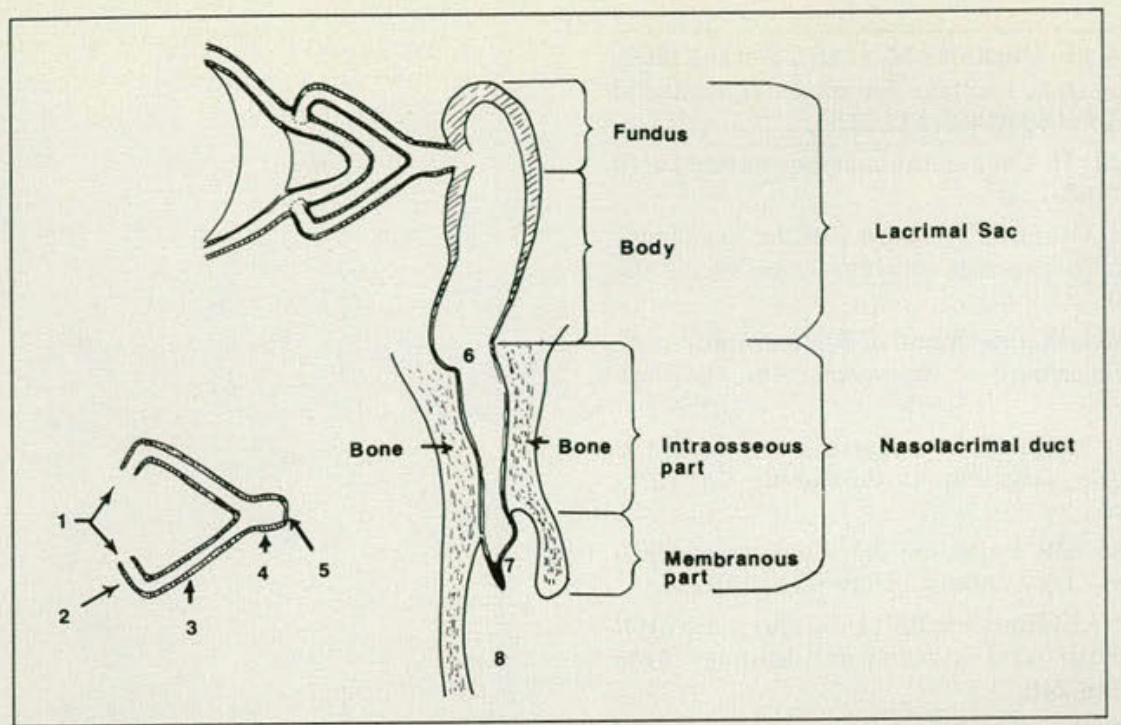

Figure 3. Lacrimal apparatus-1: superior and inferior puncta; 2 and 3. vertical and horizontal segments of the canaliculi; 4 : common canaliculus (sinus of Maier); 5: valve of Rosenmüller; 6: valve of Krause; 7: Hasner's valve (membrane); and 8: inferior nasal meatus.

ported anomaly. There have been only two cases reported describing a dacryocystocele (lacrimal sac mucocele) associated with intranasal extension. ${ }^{78}$ Divine $^{7}$ postulates that these intranasal masses are the result of nasal mucosa outpouchings at the imperforate valves of Hasner, which dissected free from the underlying tissues and ballooned outward by the back pressure in the lacrimal sac.

This condition is well demonstrated by CT, ${ }^{8}$ but to our knowledge, it has never been described by MRI characteristics. Magnetic resonance imaging clearly delineates the mass of a distended nasolacrimal sac, and its signal intensity helps to characterize the cyst contents. Predominantly, mucoid secretions should demonstrate high-signal intensity on both $\mathrm{T}_{1}$ - and $\mathrm{T}_{2}$-weighted images, while amniotic fluid or tears should follow the signal characteristics of water (low signal on $\mathrm{T}_{1}$ - and $\mathrm{T}_{2}$ weighted images). Because our case had intermediate-signal intensity on $\mathrm{T}_{1}$-weighted images and high-signal intensity on both intermediate and $\mathrm{T}_{2}$-weighted images, the cyst contents probably included some degree of mucoid elements. However, as pointed out earlier, the fluid contents within the dacryocystocele usually represents a continuum of vari- ous products such as mucus, amniotic fluid, tears, or pyogens.

The management of this condition is dependent on the clinical signs of infection or persistent prolonged dilation of the lacrimal drainage apparatus. Therefore, characterization of the cyst contents, although of academic interest, is not a prerequisite in the ultimate management scheme.

\section{Conclusion}

We present a rare case of lacrimal sac distension, secondary to a dacryocystocele, with associated intranasal extension. The MRI characteristics are described and correlated with those on CT scans. Both CT and MRI show nearly equal sensitivity in the detection of dacryocystocele; however, MRI has the advantage of (1) characterizing the fluid contents within the distended lacrimal sac; (2) allowing easy multiplanar images with patient manipulation; and (3) lacking radiation exposure to the eyes. Computed tomography, in contrast, has the advantage of demonstrating bony expansion along the nasolacrimal canal. Clinically, congenital dacryocystoceles usually resolve spontaneously and only rarely do they require surgical intervention. 
1. Russell EJ, Czervionke L, Huckman M, et al: CT of the inferomedial orbit and the lacrimal drainage apparatus: Normal and pathologic anatomy. AJR 1985;145:1147-1154.

2. Harris GJ, DiClementi D: Congenital dacryocystocele. Arch Ophthalmol 1982;100:1763-1765.

3. Muller KM, Busse H, Osmers F: Anatomy of the naso-lacrimal duct in new-borns: Therapeutic considerations. Eur J Pediatr 1978;129(2):83-92.

4. Cibis GW, Spurney RO, Waeltermann J: Radiographic visualization of congenital lacrimal sac mucoceles. Ann Ophthalmol 1986;18(2):68-69.

5. Jones LT, Wobig JL: Surgery of the Eyelids and Lacrimal System Birmingham, Ala, Aegculapius Publishing Co, 1976, p 162.

6. Weinstein GS, Biglan AW, Patterson JH: Congenital lacrimal sac mucoceles. Am J Ophthalmol 1982;94(1):106-110.

7. Divine RD, Anderson RL, Bumsted RM: Bilateral congenital lacrimal sac mucoceles with nasal extension and drainage. Arch Ophthalmol 1983;101:246-248.

8. Raflo GT, Horton JA, Sprinkle PM: An unusual intranasal anomaly of the lacrimal drainage system. Ophthalmic Surg 1982;13:741-744.

9. Scott WE, Fabre JA, Ossoinig KC: Congenital mucocele of the lacrimal sac. Arch Ophthalmol 1979;97:1656-1658. 